\begin{tabular}{|c|c|}
\hline Proceeding of the $9^{\text {th }}$ ICEE Conference 3-5 April 2018 & NCA \\
Military Technical College \\
Kobry El-Kobbah, \\
Cairo, Egypt
\end{tabular}

NCA-2

\title{
Preparation and in vitro Characterization of Chitosan Nanoparticles loaded with Ciprofloxacin Hydrochloride
}

\author{
Kotb MA ${ }^{1}$, Ramadan $\mathrm{HS}^{2}$, Hazzah $\mathrm{WA}^{3}$,_Khedr YI ${ }^{4}$ Abd-Elaziz MM${ }^{5}$
}

\begin{abstract}
Ciprofloxacin hydrochloride is a broad spectrum antibiotic, effective against various types of micro-organisms but its controlled release formulation is recommended due to its short biological half-life (4 hrs). It was the aim of the present work to prolong its release after administration. So, Ciprofloxacin $\mathrm{HCl}$ loaded Chitosan Nanoparticles were prepared by the ionic gelation method. Characterization and evaluation of the in vitro release of Chitosan Nanoparticles loaded with Ciprofloxacin hydrochloride were studied. The data of the study clearly demonstrated that, Ciprofloxacin $\mathrm{HCl}$ loaded Chitosan Nanoparticles were $60.175 \pm 4.973 \mathrm{~nm}$ in size with almost $90.713 \%$ Ciprofloxacin $\mathrm{HCl}$ encapsulation efficiency. The TEM micrographs showed that the Nanoparticles surface looked spherical or oval and Ciprofloxacin $\mathrm{HCl}$ incorporation increases size of Nanoparticles loaded with Ciprofloxacin $\mathrm{HCl}$ compared to the empty ones. In vitro release of Ciprofloxacin $\mathrm{HCl}$ from Ciprofloxacin $\mathrm{HCl}$ loaded $\mathrm{CS}$ Nanoparticles was determined in phosphate buffered saline (PBS, $\mathrm{pH} 7.4$ ), and the data showed an initial burst release followed by slow sustained drug release rate (81.698\% within 24 hour ). These observations suggest that the Nanoparticles prepared by ionic gelation process without using harsh organic chemicals might be recommended as a controlled drug delivery systems to improve efficacy, reduce toxicity, and improve patient compliance.
\end{abstract}

\section{Keywords:}

Ciprofloxacin $\mathrm{HCl}$, Chitosan Nanoparticles, Ionic gelation method.

1, 2 Dept. of Medical- Biophysics, Medical Research Institute, Alexandria University

3 Dept. of Microbiology, High Institute of Public Health, Alexandria University.

4 Dept. of Physics, Faculty of Science, Damanhur University, Egypt.

5 in Medical- Biophysics, Medical Research Institute, Alexandria University 


\section{Military Technical College \\ Kobry El-Kobbah, Cairo, Egypt}

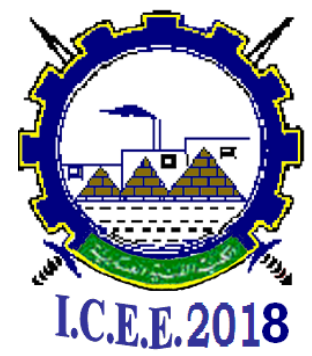

$9^{\text {th }}$ International Conference on

Chemical \& Environmental Engineering

3-5 April 2018

\section{Introduction}

Controlled drug delivery systems offer numerous advantages over conventional dosages forms, including improved efficacy, reduce toxicity, and improved patient compliance, and can be utilized in the form of nanocarriers in drug delivery. [1] Nanoparticles are defined as particles of dimensions ranging between 1 - $100 \mathrm{~nm}$ (nanometer) are designed and used for diagnostics, therapeutics and as biomedical tools for research. [2] Nanoparticulate systems show their promise as a potential ideal drug delivery system for poorly soluble, poorly absorbed and labile substances. [3]

The role of nanocarriers can be explained by four categories; it may (i) protect a drug from degradation, (ii) enhance drug absorption by facilitating diffusion through epithelium, (iii) modify pharmacokinetic and drug tissue distribution profile, and/or (iv) improve intracellular penetration and distribution. [4]

Chitosan (CS) is a natural cationic polysaccharide obtained by the $\mathrm{N}$-deacetylation of chitin, a product found in the shells of crustaceans.[5] It has been used as a Nanoparticle material owing to its natural origin, versatile hydrophilicity ,solubility biodegradability, and biocompatibility permit the design of Nanoparticles capable of protecting the loaded drug and controlling its release. [6]

It has been reported that chitosan Nanoparticles have an excellent capacity for associating proteins. [7] The interaction of chitosan and polyanions leads to the spontaneous formation of Nanoparticles in an aqueous environment without the need for heating or the use of organic solvents. [8] In addition, a high level of drug entrapment can be achieved so that the protein secondary structure and biological activity are preserved. [9]

Ciprofloxacin hydrochloride (Ciprofloxacin $\mathrm{HCl}$ ) is a broad spectrum Antibiotic, effective against various types of micro-organisms but possess a short biological half life i.e. $4 \mathrm{hrs}$ so repeated administration is needed to maintain the blood plasma concentration of Ciprofloxacin $\mathrm{HCl}$ within therapeutic level. Therefore, in order to reduce the adverse effects due to frequent dosing, there is a need of a controlled release formulation. [4]

\section{Materials and Methods}

\subsection{Materials:}

Chitosan ; ACROS (ORGANICS)- Molecular weight 100-300 KDa, Ciprofloxacin Hydrochloride (MW $385.82 \mathrm{~g} / \mathrm{mol}$ ) and Sodium Tripolyphosphate Pentabasic (MW $367.86 \mathrm{~g} / \mathrm{mol})$; SIGMA-ALDRICH. All other solvents and materials used were of analytical grade. 
Military Technical College

Kobry El-Kobbah, Cairo, Egypt

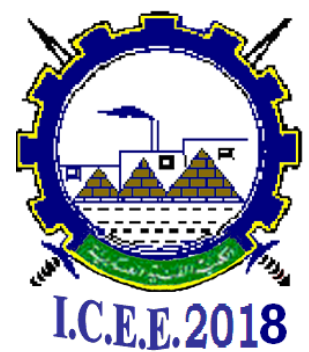

$9^{\text {th }}$ International Conference on

Chemical \& Environmental

Engineering

3-5 April 2018

\subsection{Methods}

2.2.1. Preparation of Chitosan and Ciprofloxacin Hydrochloride loaded Chitosan Nanoparticles:

Chitosan Nanoparticles (CSNPs) were prepared by ionic gelation method [10]. Two $(\mathrm{mg} / \mathrm{ml})$ of Chitosan was dissolved in $1 \%(\mathrm{w} / \mathrm{v})$ acetic acid and sonicated before the solution became transparent. TPP solution was added at a concentration of $0.7 \mathrm{mg} / \mathrm{ml}$ drop wise, to equal volume of CS solution, under continuous stirring at $500 \mathrm{rpm}$ for 30 minutes at room temperature. The resulting opalescent suspension was determined as CSNPs. The same procedures were done for preparation of Chitosan Nanoparticles loaded with Ciprofloxacin $\mathrm{HCl}$, in the presence of $0.05 \mathrm{gm}$ that was dispersed in $100 \mathrm{ml}$ of CS solution. The resulting opalescent suspension was determined as Ciprofloxacin $\mathrm{HCl}$ loaded with Chitosan Nanoparticles. Reaction mixture was centrifuged at $11000 \mathrm{rpm}$ at $4^{\circ} \mathrm{C}$ for 30 mins using high speed cooling centrifuge (Sigma, Germany). The supernatant was decanted and Nanoparticles were suspended in sterile distilled water and recentrifuged at $11000 \mathrm{rpm}$ at $4^{\circ} \mathrm{C}$ for 30 minutes to separate the Nanoparticles.

\subsubsection{Characterization of Chitosan and Ciprofloxacin Hydrochloride loaded with Chitosan Nanoparticles}

\subsubsection{Transmission electron microscopy (TEM)}

The morphology and size of the Nanoparticles were performed by Transmission Electron Microscopy (TEM, JEOL $100 \mathrm{CX}$ ). The sample was prepared by placing a drop of the sample on a carbon-coated copper grid and left to dry in air, before transferring to TEM.

\subsubsection{Zetasizer measurements}

The polydispersity index (PDI) and Zeta potential $(\zeta)$ were determined using Zetasizer (ZS), (Nano-ZS, Malvern, UK). The measurement was carried out in disposable polystyrene cuvettes at $25^{\circ} \mathrm{C}$ with measurement angle of $12.8^{\circ}$ and $175^{\circ}$.

\subsubsection{Determination of entrapment efficiency (EE)}

To determine the EE after preparation of Ciprofloxacin Hydrochloride loaded NPs ,the sample was centrifuged at $11000 \mathrm{rpm}$ for 30 mins then the supernatant was discarded at which free Ciprofloxacin Hydrochloride was measured using UV-visible spectrophotometer at $277 \mathrm{~nm}$ using UV-spectrophotometer (Helios Alpha, Unicam). Ciprofloxacin $\mathrm{HCl}$ entrapment efficiency was calculated by using the following formula.

[4]

$$
\begin{aligned}
& \text { \%Ciprofloxacin encapsulation efficiency (C.E. E) } \\
& =\frac{(\text { Total amount of Ciprofloxacin } \mathrm{HCl}-\text { Free amount of Ciprofloxacin } \mathrm{HCl}) \times 100}{}
\end{aligned}
$$

Total amount of Ciprofloxacin $\mathrm{HCl}$ 
Military Technical College

Kobry El-Kobbah, Cairo, Egypt

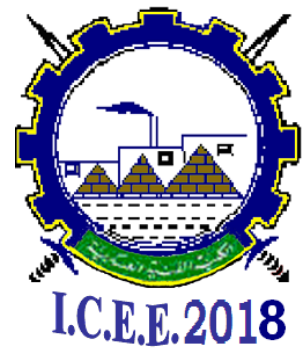

$9^{\text {th }}$ International Conference on

Chemical \& Environmental Engineering

3-5 April 2018

\subsubsection{In vitro release of Ciprofloxacin $\mathrm{HCl}$ from Ciprofloxacin $\mathrm{HCl}$ loaded Chitosan Nanoparticles:}

In vitro release of Ciprofloxacin $\mathrm{HCl}$ from Ciprofloxacin $\mathrm{HCl}$ loaded CS Nanoparticles was determined in phosphate buffered saline (PBS, $\mathrm{pH} 7.4$ ) at $37^{\circ} \mathrm{C}$ with mild agitation. At predetermined time intervals, $1 \mathrm{ml}$ of mixture was taken and centrifuged at $11000 \mathrm{rpm}$ at $4^{\circ} \mathrm{C}$ for 30 minutes. Ciprofloxacin $\mathrm{HCl}$ content was measured in the supernatant using UV spectroscopy at $271 \mathrm{~nm}$ and equal volume of freshly prepared medium was supplemented.

\section{Result and Discussion}

\subsection{Preparation of Chitosan and Ciprofloxacin HCl loaded Chitosan Nanoparticles} Chitosan Nanoparticles (CSNPs) can easily be prepared by the ionic gelation method using Tripolyphosphate (TPP) as a crosslinking agent. The advantage of this method is attributed to its mild conditions achieved without applying harmful organic solvent, heat or vigorous agitation that are damaging to sensitive proteins. Moreover, it could efficiently retain the bioactivity of macromolecules (such as DNA, proteins, etc.) during preparation. [11] CSNPs spontaneously form via the electrostatic interaction between positively charged primary amino groups on Chitosan chains and reversely charged TPP as shown in Figure (1). It has been reported that Chitosan Nanoparticles have an excellent capacity for associating proteins. [7] Chitosan is a cationic polymer (due to protonation of amine groups in acidic $\mathrm{pH}$ ) possessing functional groups on its structure facilitating effective encapsulation of bio-molecules like Ciprofloxacin Hydrochloride. Ciprofloxacin $\mathrm{HCl}$ loaded Chitosan Nanoparticles form via the electrostatic interaction between positively charged primary amino groups on Chitosan chains and negatively charged $\mathrm{COOH}$ group of Ciprofloxacin $\mathrm{HCl}$, So Ciprofloxacin $\mathrm{HCl}$ loaded Chitosan Nanoparticles can be prepared by the ionic gelation as shown in Figure (2). [4, 12]

\subsection{Characterization of Chitosan Nanoparticles}

\subsubsection{Transmission electron microscopy (TEM)}

Ciprofloxacin $\mathrm{HCl}$ incorporation increases particle size of Nanoparticles compared to empty Nanoparticles .The empty Nanoparticles were found to have an average particle size of $33.938 \pm 2.269 \mathrm{~nm}$, while Ciprofloxacin $\mathrm{HCl}$ loaded Chitosan NPs were found to have an average size of $60.175 \pm 4.973 \mathrm{~nm}$. Nanoparticles surface looked spherical and /or oval as shown in Figures ( $3 \& 4$ ). 


\section{Military Technical College \\ Kobry El-Kobbah, Cairo, Egypt}

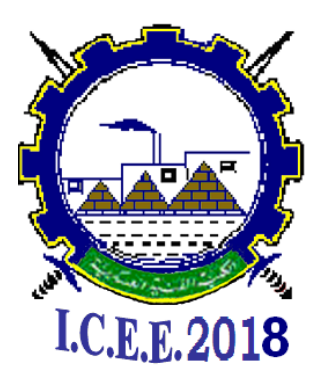

$9^{\text {th }}$ International Conference on

Chemical \& Environmental Engineering

3-5 April 2018

\subsubsection{Zetasizer measurements}

Zeta potential of Nanoparticles is commonly used to characterize the surface charge property of Nanoparticles. It reflects the electrical potential of particles and is influenced by the composition of the particle and the medium in which it is dispersed. Nanoparticles with a Zeta potential above $( \pm) 30 \mathrm{mV}$ have been shown to be stable in suspension, as the surface charge prevents aggregation of the particles. [13]

As expected, the Zeta potential of Chitosan is positive due to presence of amino groups. All Ciprofloxacin $\mathrm{HCl}$ loaded Chitosan Nanoparticles displayed a lower positive Zeta potential in comparison with the free Chitosan Nanoparticles. The ratio of negative charge (Ciprofloxacin $\mathrm{HCl}$ ) to positive charge of Chitosan remains in favour of positive charge of Chitosan Nanoparticles as shown in Figures (5 and 6). Only a small fraction is neutralized by binding Ciprofloxacin $\mathrm{HCl}$, this indicated that partial neutralization of Chitosan charge took place. This is agree well with the results reported by Sadeghi et al. (2008). [14]

Dash et al. (2013), [4] prepared Ciprofloxacin HCl Nanoparticles with Particle Size of $457 \mathrm{~nm}$ and Zeta potential of $38.6 \mathrm{mV}$ which agreed with our results as Zeta potential was above $30 \mathrm{mV}$.

The polydispersity index (PDI) closes to zero indicates a homogeneous dispersion, and those greater than 0.5 indicate high heterogeneity .The PDI for both Chitosan Nanoparticles and Ciprofloxacin $\mathrm{HCl}$ loaded Chitosan Nanoparticles is smaller than 0.5, which indicates a relative homogenous dispersion as shown in Table (1). The residual amine groups of Chitosan would be responsible for positive Zeta potential. It seems that higher Zeta potential in the determined range leads to more stable Nanoparticles, which in turns prevent the aggregation. Polydispersity indicates the degree of nonuniformity of the particle size. Obviously, a low polydispersity indicates more uniformity in size distribution. $[13,15]$

\subsection{Determination of entrapment efficiency (EE)}

Ciprofloxacin $\mathrm{HCl}$ encapsulation efficiency in this work was $90.713 \%$, A lower concentration found in the supernatant implies a higher loading efficiency in the Chitosan Nanoparticles. [16] The high EE value could be attributed to the electrostatic interaction between between positively charged primary amino groups on Chitosan chains (due to protonation of amine groups in acidic $\mathrm{pH}$ ) and negatively charged $\mathrm{COOH}$ group of Ciprofloxacin HCL facilitating effective encapsulation of Ciprofloxacin Hydrochloride using ionic gelation method $[4,17]$. 
Military Technical College

Kobry El-Kobbah, Cairo, Egypt

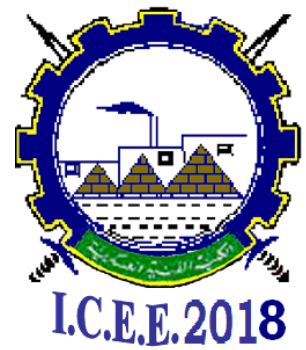

$9^{\text {th }}$ International Conference on

Chemical \& Environmental

Engineering

3-5 April 2018

\subsection{In vitro Ciprofloxacin $\mathrm{HCl}$ release profile from Ciprofloxacin $\mathrm{HCl}$ loaded Chitosan Nanoparticles determined in phosphate buffered saline (PBS, pH 7.4)}

In vitro release of Ciprofloxacin $\mathrm{HCl}$ from Ciprofloxacin $\mathrm{HCl}$ loaded $\mathrm{CS}$ Nanoparticles was determined in phosphate buffered saline (PBS, $\mathrm{pH}$ 7.4). The average cumulative percent release profile and the average cumulative release profile of Ciprofloxacin $\mathrm{HCl}$ loaded CS Nanoparticles at prefixed time intervals as a function of time is represented in Figures $(7 \& 8)$ and in Tables $(2 \& 3)$. A sustained release profile was observed and Ciprofloxacin $\mathrm{HCl}$ was released for 24 hours. Ciprofloxacin $\mathrm{HCl}$ loaded Chitosan Nanoparticles showed drug release $81.698 \%$ within 24 hours give release pattern in controlled manner. Ciprofloxacin $\mathrm{HCl}$ loaded Chitosan Nanoparticles give burst release followed by sustained release as controlled manner. For the initial $1 \mathrm{hr}$, only $54.378 \%$ Ciprofloxacin $\mathrm{HCl}$ release was observed but over $24 \mathrm{hrs} 81.698 \%$ of encapsulated Ciprofloxacin $\mathrm{HCl}$ was released. The burst release of Ciprofloxacin from Nanoparticles at initial stage resulted from the dissolution of drug crystals on the surface of Nanoparticles. [4,18] Generally, drug release follows more than one type of mechanisms. In case of release from the surface, drug adsorbed on the surface of Nanoparticles dissolves instantaneously when it comes in contact with the release medium. The early phase of the release corresponds to the release of drugs physically bound to the surface of the Nanoparticles and the delayed phase due to the release of entrapped drug due to diffusion of drug from the rigid matrix structure. [19]

Dash et al.(2013), [4] prepared Ciprofloxacin HCl Nanoparticles with particle size of 457 $\mathrm{nm}$ using ionic gelation method and the cumulative percentage of drug release was about $85 \%$ within 24 hours. The prepared Nanoparticles release the drug in a controlled manner and the polymer used was nontoxic, biocompatible and freely available and act as a good carrier of the therapeutic agents. As the Ciprofloxacin has a short biological halflife, the controlled release formulation of Ciprofloxacin is recommended.

Kumar et al.(2011), [18] prepared and characterized Chitosan Nanoparticles loaded with Amoxycillin. According to this study, Kumar et al, reported that the release of drug from Nanoparticles exhibited a prolonged release profile (79\%) as studied over 28 hours. The drug release was constant showed the formulation as long term treatment this study showed that Chitosan can complex TPP to form stable Nanoparticles for amoxicillin loading, which can be useful for microbial therapy. 
Military Technical College

Kobry El-Kobbah,

Cairo, Egypt

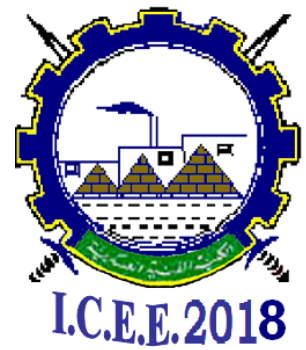

$9^{\text {th }}$ International Conference

on

Chemical \& Environmental

Engineering

3-5 April 2018

\section{Conclusion}

As the Ciprofloxacin has a short biological half-life, the controlled release formulation of Ciprofloxacin is recommended. The prepared Nanoparticles release the drug in a controlled manner and the used polymer was nontoxic, biocompatible and freely available and acts as a good carrier of the therapeutic agents. Therefore, based on the following characteristics, a new Nanoparticulate dosage form prepared by ionic gelation process, without using harsh organic chemicals, might be employed as a controlled drug delivery systems to improve efficacy, reduce toxicity, and improve patient compliance .

So, it can be concluded that:

- In vitro drug release pattern (the Ciprofloxacin $\mathrm{HCl}$ loaded CSNPs releases the drug in a controlled manner).

- The characteristics of the used polymer (Chitosan) are: nontoxic, biocompatible and freely available and also acting as a good carrier of the therapeutic agents.

\section{References}

[1] MN. Ravi Kumar, Nano and microparticles as controlled drug delivery devices, J. Pharm. Pharm. Sci. 3 (2000) 234-258.

[2] C. Medina, MJ. Santos-Martinez, A. Radomski, OI. Corrigan, MW. Radomski, Nanoparticles: pharmacological and toxicological significance, Br. J. Pharmacol. 150 (2007) 552-558.

[3] F. Delie, Evaluation of nano- and microparticle uptake by the gastrointestinal tract, Adv. Drug Deliv. Rev.34 (1998) 221-233.

[4] AK. Dash, J. Mishra, Formulation and in vitro characterization of chitosannanoparticles loaded with ciprofloxacin hydrochloride, Der Pharmacia Lettre.5 (2013) 126-131.

[5] S. Mansouri, P. Lavigne, K. Corsi, M. Benderdour, E. Beaumont, JC. Fernandes, Chitosan-DNA nanoparticles as non-viral vectors in gene therapy: strategies to improve transfection efficacy, Eur. J. Pharm. Biopharm. 57 (2004) 1-8.

[6] RB. Umamaheswari, S. Jain, PK. Tripathi, GP. Agrawal, NK. Jain, Floatingbioadhesive microspheres containing acetohydroxamic acid for clearance of Helicobacter pylori, Drug. Deliv. 9 (2002) 223-231.

[7] R. Fernández-Urrusuno, P. Calvo, C. Remuñan-López, JL. Vila-Jato, MJ. Alonso, Enhancement of nasal absorption of insulin using chitosan nanoparticles, Pharm Res. 16 (1999) 1576-1581. 
Military Technical College

Kobry El-Kobbah, Cairo, Egypt

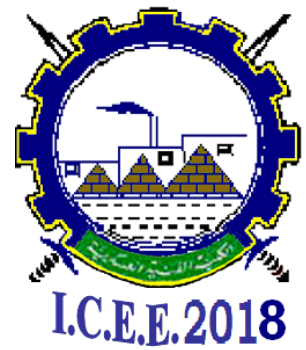

$9^{\text {th }}$ International Conference on

Chemical \& Environmental

Engineering

3-5 April 2018

[8] Q. Gan, T. Wang, Chitosan nanoparticle as protein delivery carrier--systematic examination of fabrication conditions for efficient loading and release, Colloids Surf B Biointerfaces. 59 (2007) 24-34.

[9] A. Chaudhury, S Das, Recent advancement of chitosan-based nanoparticles for oral controlled delivery of insulin and other therapeutic agents, AAPS Pharm Sci Tech. 12 (2011) 10-20.

[10] P Calvo, C. Remunan-Lopez, JL. Vila-Jato, MJ. Alonso, Novel Hydrophilic Chitosan-Polyethylene Oxide Nanoparticles as Protein Carrier, J. Appl Poly Sci. 63 (1997) 125-132.

[11] Y. Pan, YJ. Li, HY. Zhao, JM. Zheng, H. Xu, G. Wei, JS. Hao, FD. Cui, Bioadhesive Polysaccharide in Protein Delivery System: Chitosan Nanoparticles Improve the Intestinal Absorption of Insulin In Vivo, Int. J. Pharm. 249 (2002) 139147.

[12] P. Saha, AK. Goyal, G. Rath, Formulation and Evaluation of Chitosan-Based Ampicillin Trihydrate Nanoparticles, Trop J Pharm Res. 9 (2010) 483-488.

[13] RA. Balajia, S. Raghunathana, R. Revathy, Levofloxacin: Formulation and In-Vitro Evaluation of Alginate and Chitosan Nanospheres. Egypt Pharm J. 14 (2015)30-35.

[14] AM. Sadeghi, FA. Dorkoosh, MR. Avadi, P. Saadat, M. Rafiee-Tehrani, HE. Junginger, Preparation, Characterization and Antibacterial Activities of Chitosan, NtrimethylChitosan.TMC; and N-dimethyl Chitosan.DEMC; Nanoparticles Loaded with Insulin Using Both the Inotropic Gelation and Polyelectrolyte Complexation Methods, Int J Pharm.355 (2008) 299-306.

[15] W. Ye, MF. Leung, J. Xin, TL. Kwong, DKL. Lee, P. Li, Novel Core-Shell Particles with Poly (n-butyl acrylate) Cores and Chitosan Shells as an Antibacteial Coating for Textiles, Polymer.46 (2005) 10538-10543.

[16] H. Liu, C. Gao, Preparation and Properties of Ionically Cross-Linked Chitosan Nanoparticles, Polym Adv Technol. 20 (2009) 613-619.

[17] A. Semwal, BK. Singh, PK Dutta, D. Archana, A. Verma, Macromolecular Chitosan/ Ciprofloxacin Pro-Drugs: Synthesis, Physico-chemical and Biological Assessment for Drug Delivery Systems, J. Polym Mater. 29 (2012) 1-13.

[18] DA. Kumar, PP. Shiv, N. Shrikant, M. Jhansee, S. Dharmendra, Development and Characterization of Chitosan Nanoparticles Loaded With Amoxycillin, IRJP.2 (2011) 145-151.

[19] D. Jain, R. Banerjee, Comparison of Ciprofloxacin Hydrochloride-Loaded Protein, Lipid, and Chitosan Nanoparticles for Drug Delivery, J. Biomed Mater Res Part B: Appl Biomater. 86B (2008) 105-112. 
Military Technical College

Kobry El-Kobbah, Cairo, Egypt

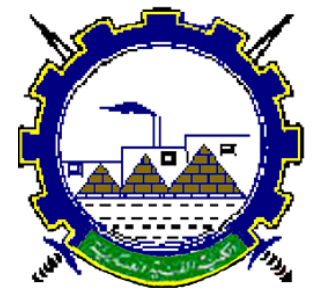

I.C.E.E.2018 $9^{\text {th }}$ International Conference on

Chemical \& Environmental Engineering 3-5 April 2018

[20] CB. Woitiski, RJ. Neufeld, AJ. Ribeiro, F. Veiga, Colloidal carrier integrating biomaterials for oral insulin delivery: influence of component formulation on physicochemical and biological parameters, Acta Biomater.5 (2009)2475-2484. 
Military Technical College Kobry El-Kobbah, Cairo, Egypt

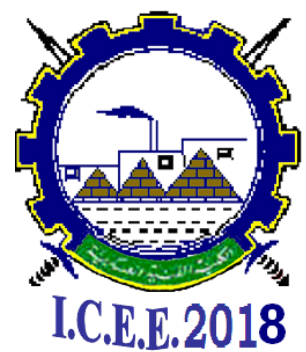

$9^{\text {th }}$ International Conference on

Chemical \& Environmental Engineering 3-5 April 2018

Table 1: Zeta potential and Polydispersity index (PDI) of Chitosan Nanoparticles and Ciprofloxacin $\mathrm{HCl}$ loaded Chitosan Nanoparticles measured by Zetasizer.

\begin{tabular}{|c|c|c|}
\hline Parameter & $\begin{array}{c}\text { Zeta potential } \\
\boldsymbol{\zeta}(\mathbf{m V})\end{array}$ & PDI \\
\hline $\begin{array}{c}\text { Chitosan Nanoparticles Free from } \\
\text { Ciprofloxacin HCl }\end{array}$ & $53.2 \mathrm{mV} \pm 5.16$ & $0.447 \pm 0.0213$ \\
\hline $\begin{array}{c}\text { Ciprofloxacin HCl loaded Chitosan } \\
\text { Nanoparticles }\end{array}$ & $45.3 \mathrm{mV} \pm 4.15$ & $0.333 \pm 0.043$ \\
\hline
\end{tabular}

Table 2: The cumulative concentration of Ciprofloxacin $\mathrm{HCl} \mu \mathrm{g} / \mathrm{ml}$ (mean $\pm \mathrm{SD}$ ) released from Ciprofloxacin $\mathrm{HCl}$ loaded Chitosan Nanoparticles in phosphate buffer saline ( $\mathrm{pH} 7.4)$ for 24 hours.

\begin{tabular}{|c|c||}
\hline Time (hours) & $\begin{array}{c}\text { The cumulative concentration of Ciprofloxacin HCl } \\
\text { Mean }(\boldsymbol{\mu g} / \mathbf{m l}) \mathbf{\pm S D}\end{array}$ \\
\hline 0 & $0.000 \pm 0.000$ \\
\hline 0.5 & $22.933 \pm 0.042$ \\
\hline 1 & $30.830 \pm 0.037$ \\
\hline 2 & $31.318 \pm 0.024$ \\
\hline 4 & $32.631 \pm 0.030$ \\
\hline 6 & $32.999 \pm 0.043$ \\
\hline 8 & $35.269 \pm 0.036$ \\
\hline 24 & $46.320 \pm 0.018$ \\
\hline
\end{tabular}




\begin{tabular}{|l|l|}
\hline Proceeding of the $9^{\text {th }}$ ICEE Conference 3-5 April 2018 & NCA \\
\hline
\end{tabular}

Military Technical College

Kobry El-Kobbah,

Cairo, Egypt

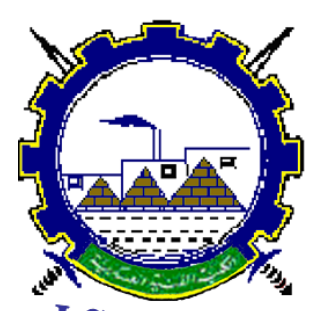

I.C.E.E.2018 $9^{\text {th }}$ International Conference on

Chemical \& Environmental

Engineering

3-5 April 2018

Table 3: The percentage of cumulative concentration of Ciprofloxacin $\mathrm{HCl}(\%)$ released from Ciprofloxacin $\mathrm{HCl}$ loaded Chitosan Nanoparticles in phosphate buffer saline $(\mathrm{pH}$ 7.4) for 24 hours.

\begin{tabular}{|c|c||}
\hline \multirow{2}{*}{ Time (hours) } & $\begin{array}{c}\text { The percentage of cumulative concentration of Ciprofloxacin HCl } \\
(\mathbf{\%})\end{array}$ \\
\hline 0 & 0.000 \\
\hline 0.5 & 40.450 \\
\hline 1 & 54.378 \\
\hline 2 & 55.239 \\
\hline 4 & 57.555 \\
\hline 6 & 58.204 \\
\hline 8 & 62.207 \\
\hline 24 & 81.698 \\
\hline
\end{tabular}


Military Technical College

Kobry El-Kobbah,

Cairo, Egypt
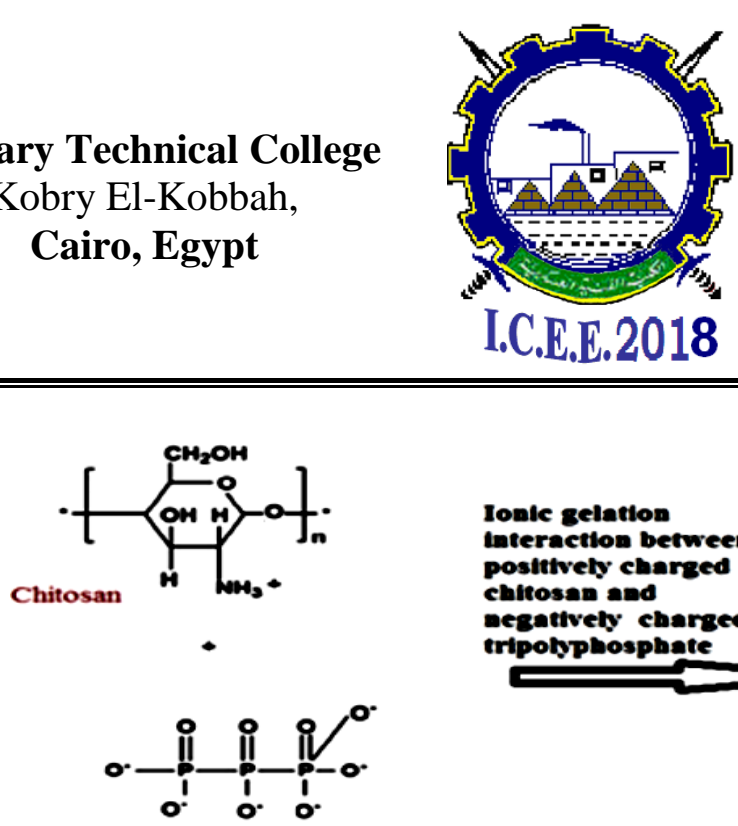

Tripolyphosphate (TPP)
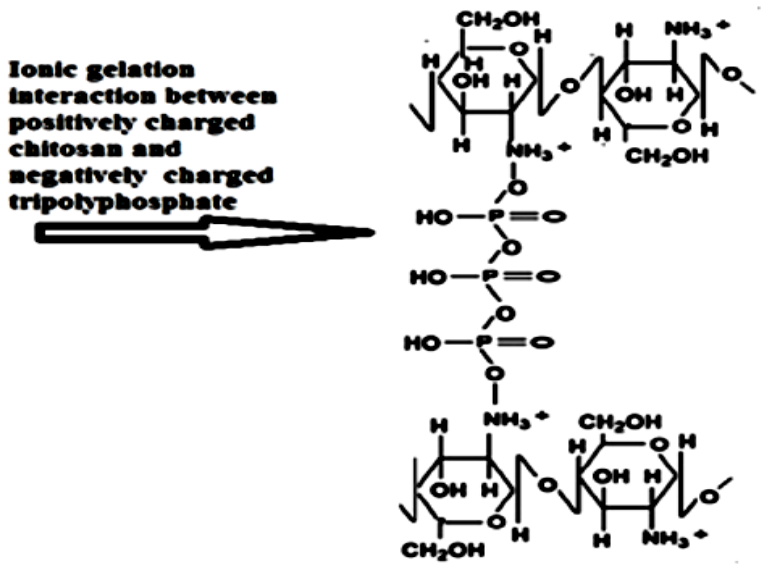

Chitosan nanoparticles $9^{\text {th }}$ International Conference on

Chemical \& Environmental

Engineering

3-5 April 2018

Fig. (1) The preparation of Chitosan Nanoparticles is based on an ionic gelation interaction between positively charged Chitosan and negatively charged

Tripolyphosphate.

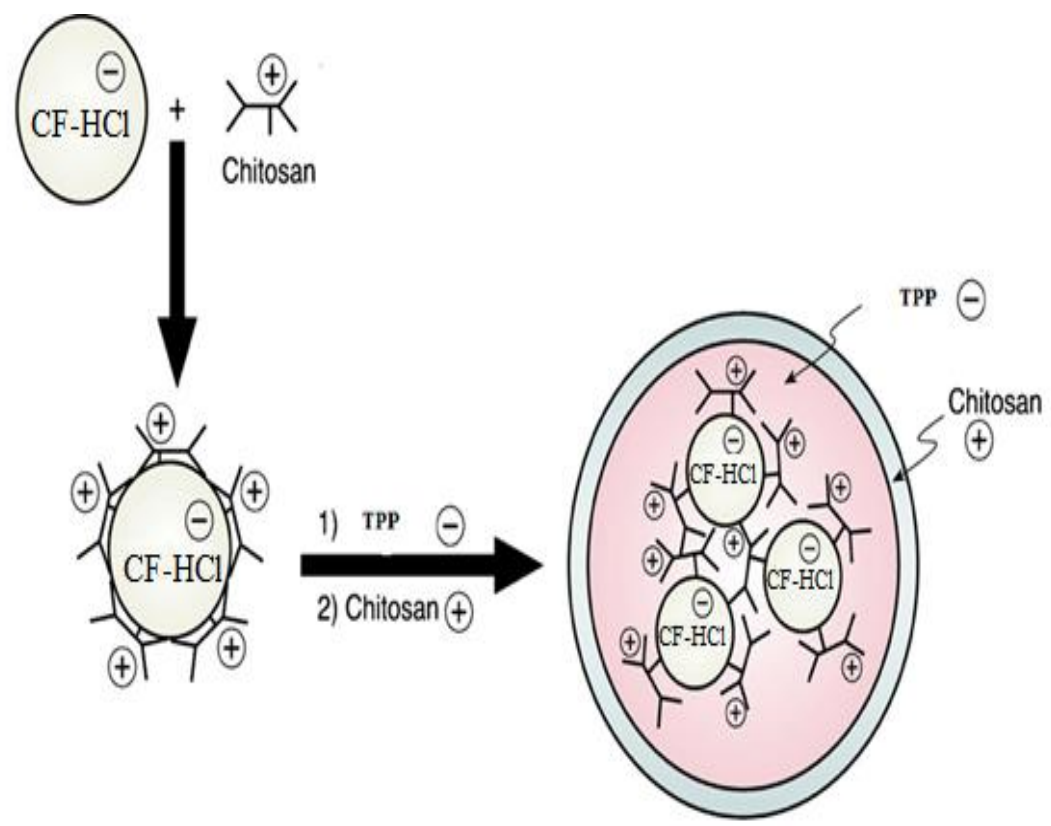

Fig. (2) The preparation of Ciprofloxacin Hydrochloride (CF-HCl) loaded Chitosan nanoparticles by the ionic gelation using Chitosan and Tripolyphosphate. Quoted and modified from [20] 


\begin{tabular}{|c|c|c|}
\hline Proceeding of the $9^{\text {th }}$ ICEE Conference 3-5 April 2018 & NCA \\
Military Technical College \\
Kobry El-Kobbah, \\
Cairo, Egypt
\end{tabular}

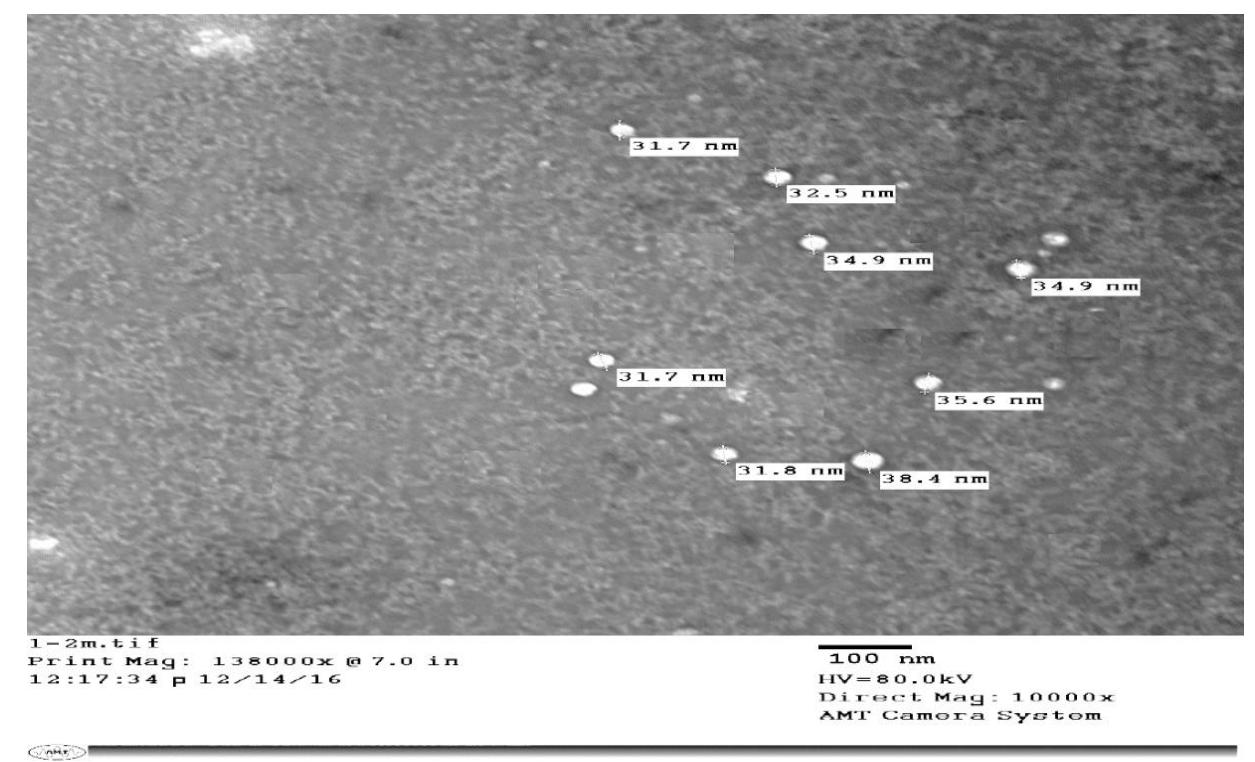

Fig. (3) TEM Micrograph of Chitosan Nanoparticles

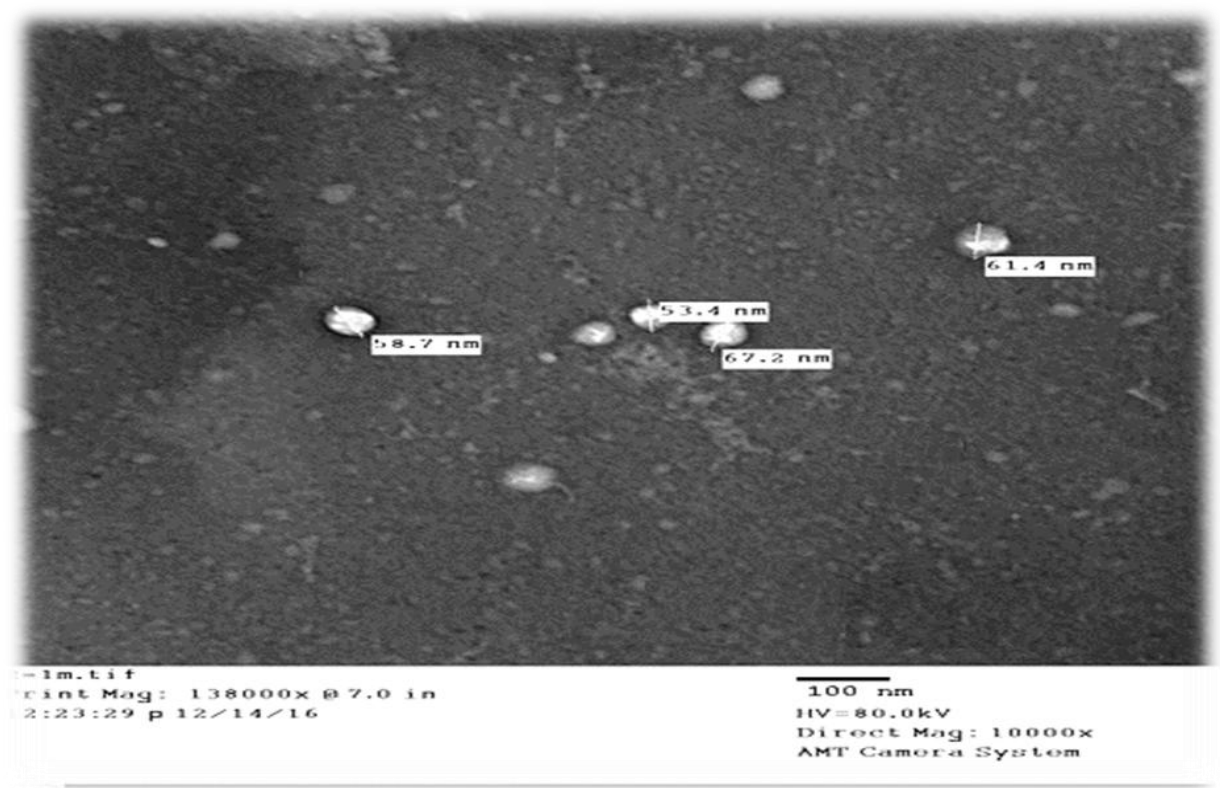

Fig. (4) TEM Micrograph of Ciprofloxacin HCl loaded Chitosan Nanoparticles. 
Military Technical College Kobry El-Kobbah, Cairo, Egypt

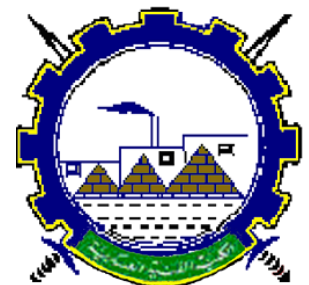

I.C.E.E.2018 $9^{\text {th }}$ International Conference on

Chemical \& Environmental

Engineering

3-5 April 2018

\begin{tabular}{|c|c|c|c|c|}
\hline & & Mean $(\mathrm{mV})$ & Area $(\%)$ & St Dev (mV) \\
\hline Zeta Potential (mV): 53.2 & Peak 1: & 53.2 & 100.0 & 5.16 \\
\hline Zeta Deviation $(\mathrm{mV}): 5.16$ & Peak 2: & 0.00 & 0.0 & 0.00 \\
\hline Conductivity $(\mathrm{mS} / \mathrm{cm}): 0.661$ & Peak 3: & 0.00 & 0.0 & 0.00 \\
\hline
\end{tabular}

Zeta Potential Distribution

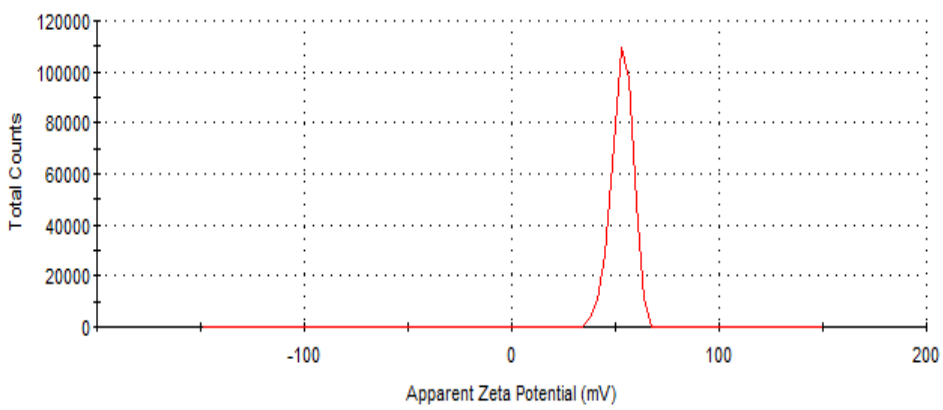

Fig. (5) The Zeta potential (mV) of Chitosan Nanoparticles measured by Zetasizer (Malvern, UK)

\begin{tabular}{|c|c|c|c|c|}
\hline & & Mean (mV) & Area (\%) & St Dev (mV) \\
\hline Zeta Potential (mV): 45.3 & Peak 1: & 45.3 & 100.0 & 4.15 \\
\hline Zeta Deviation (mV): 4.15 & Peak 2: & 0.00 & 0.0 & 0.00 \\
\hline Conductivity (mS/cm): 0.770 & Peak 3: & 0.00 & 0.0 & 0.00 \\
\hline
\end{tabular}

Zeta Potential Distribution

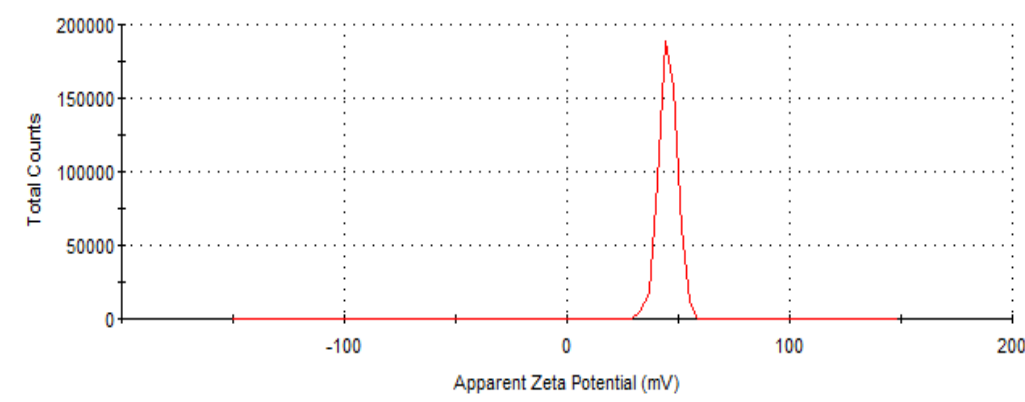

Fig. (6) The Zeta potential (mV) of Ciprofloxacin HCl loaded Chitosan Nanoparticles measured by Zetasizer (Malvern, UK). 


\begin{tabular}{|l|l|}
\hline Proceeding of the $9^{\text {th }}$ ICEE Conference 3-5 April 2018 & NCA \\
\hline
\end{tabular}

Military Technical College

Kobry El-Kobbah, Cairo, Egypt
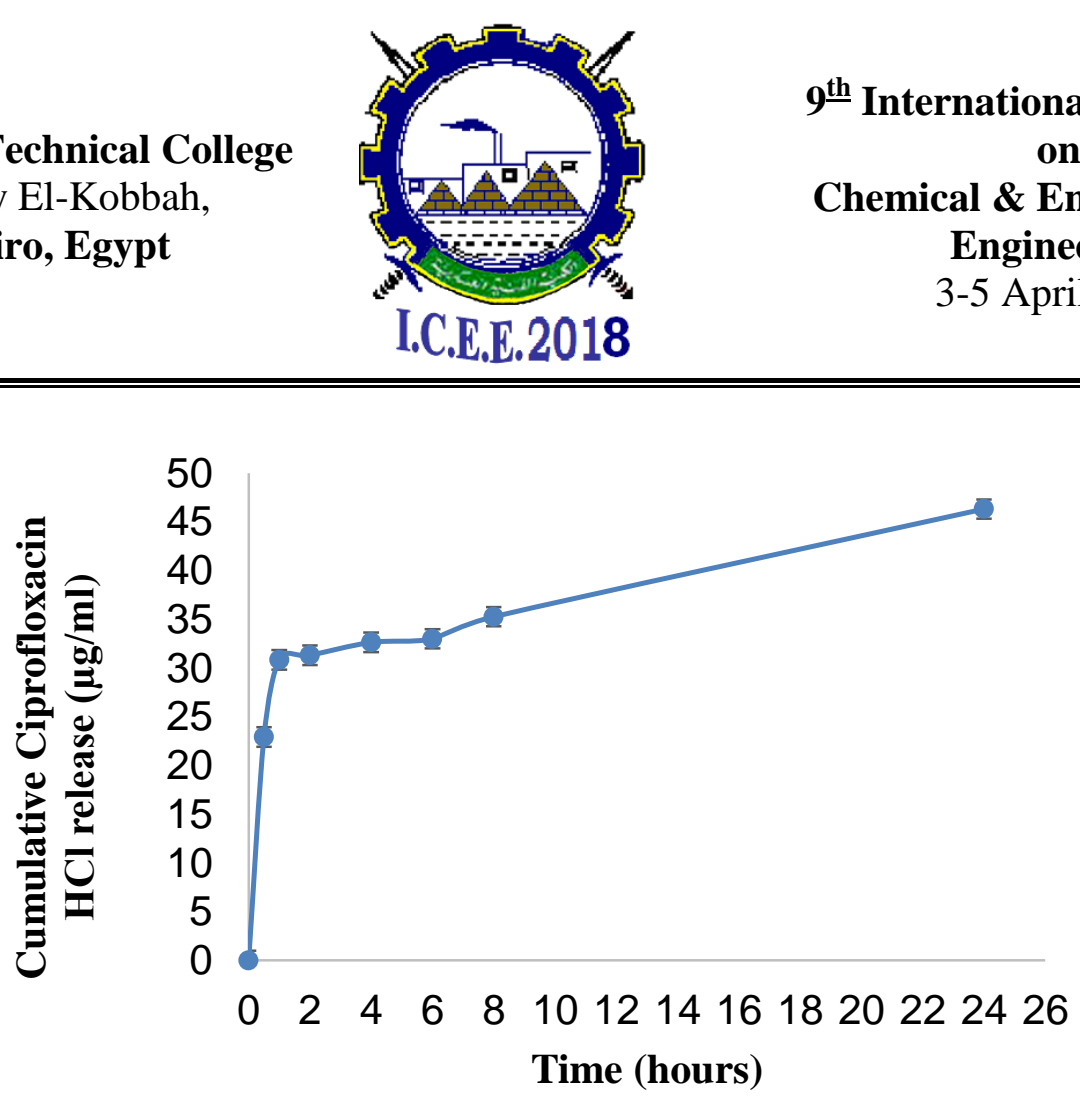

Fig. (7) Cumulative Ciprofloxacin $\mathrm{HCl}$ concentration released in vitro from Ciprofloxacin HCl loaded Chitosan Nanoparticles using phosphate buffer saline (PBS), pH 7.4

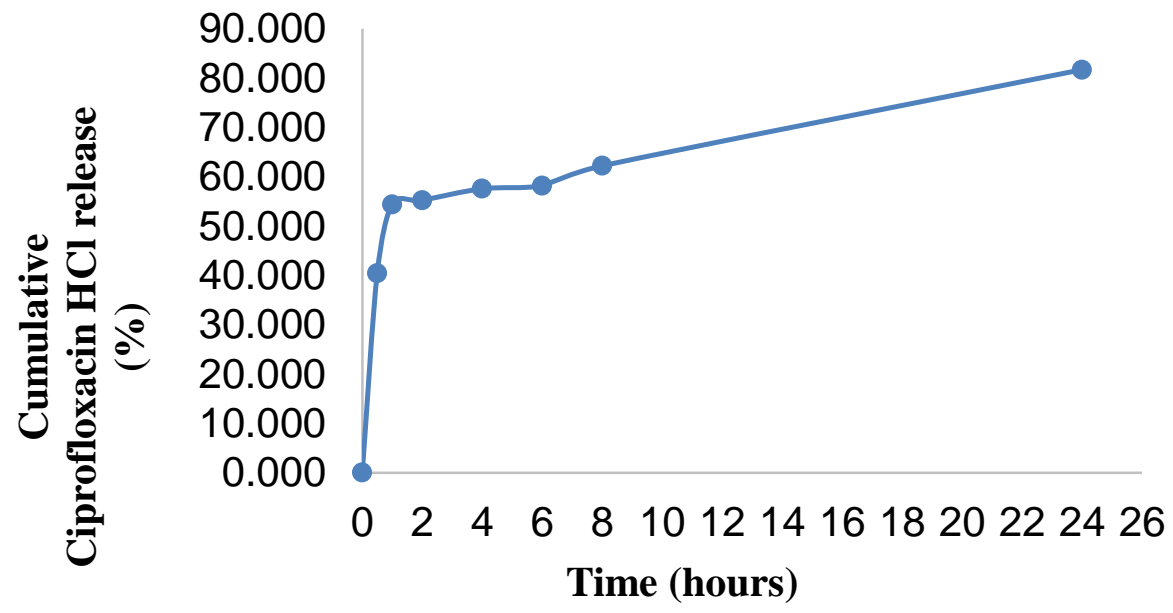

Fig. (8).Percentage of cumulative Ciprofloxacin $\mathrm{HCl}$ concentration released in vitro from Ciprofloxacin HCl loaded Chitosan Nanoparticles using Phosphate buffer saline, pH 7.4. 